\title{
Penerapan Karya desain BIG dalam Institut Kesenian Pekanbaru
}

\section{Application of BIG design work in the Pekanbaru Art Institute}

\author{
Harya Bima Prasetya ${ }^{1}$, Mira Dharma Susilawati'2) \& Gun Faisal ${ }^{3}$ ) \\ 1)Arsitektur, Fakultas Teknik, Universitas Riau, Indonesia \\ 2) Arsitektur, Fakultas Teknik, Universitas Riau, Indonesia \\ 3) Arsitektur, Fakultas Teknik, Universitas Riau, Indonesia \\ Diterima: November 2020; Disetujui: Desember 2020; Dipublikasi: April 2021 \\ *Corresponding author: harya.bima6141@student.unri.ac.id
}

\begin{abstract}
Abstrak
Pekanbaru merupakan sebuah ibu kota provinsi Riau yang mempunyai keragaman seni. Perkembangan seni di Pekanbaru dapat di lihat dari bentuk ornamen, pakaian, tarian, musik, maupun komunitas seni. Namun berdasarkan data Kemendikbud menyatakan bahwa Pekanbaru tidak mempunyai sekolah kesenian di tingkat perguruan tinggi. Dengan demikian Institut Kesenian Pekanbaru menjadi respon terhadap kebutuhan masyarakat, sebagai sebuah wadah bagi para remaja untuk mendapatkan pendidikan kesenian di tingkat perguruan tinggi, sehingga menghasilkan seniman-seniman yang profesional pada bidang kesenian. Karya BIG di pilih sebagai preseden agar terciptanya bangunan yang ikonik serta menjadi simbol pendidikan kesenian di pekanbaru. Pada penerapan karya desain BIG mempengaruhi cara pemilihan site pada kawasan pendidikan, menerapkan prinsip Hedonistic Sustainability yang menghasilkan dampak positif ke area sekitar, pemilihan konsep berupa sungai poligon yang berdasarkan bentuk sungai Siak, multi fungsi bangunan yang memiliki fungsi utama sebagai perguruan tinggi dan fungsi sekunder sebagai tempat rekreasi, mengekspos tekstur material bangunan, dan juga bagaimana mengatur organisasi ruang pada bangunan.
\end{abstract}

Kata Kunci : Seni, Institut, Pekanbaru, BIG

\begin{abstract}
Pekanbaru is the capital of Riau province which has a diversity of arts. The development of art in Pekanbaru can be seen from the form of ornaments, clothing, dance, music, and the arts community. However, based on data from the Ministry of Education and Culture, it states that Pekanbaru does not have art schools at the tertiary level. Thus the Pekanbaru Art Institute is a response to the needs of the community, as a forum for young people to get art education at the college level, so as to produce professional artists in the arts. BIG's work was chosen as a precedent for the creation of iconic buildings and symbols of art education in Pekanbaru. In the application of BIG design works affect the way site selection in the educational area, applying the Hedonistic Sustainability principle that produces a positive impact on the surrounding area, the selection of concepts in the form of polygon rivers based on the Siak river shape, multi-function buildings that have the primary function as universities and secondary functions as recreation areas, exposing the texture of building materials, and also how to organize the
\end{abstract}


organization of space in buildings.

Keywords: Art, Institute, Pekanbaru, BIG

How to Cite : Prasetya H.B, Mira D.S, Gun F (2021). Penerapan Karya Desain BIG dalam Institut Kesenian Pekanbaru. JAUR (Journal of Architecture and Urbanism Research). 4 (2): 84-96 


\section{PENDAHULUAN}

Masyarakat Pekanbaru merupakan masyarakat modern yg masih terkait dengan tradisi kesenian dan budaya, hal ini terdapat pada ciri khas bangunan, aksesoris pakaian, tradisi acara, dan juga tutur bicara. Sejatinya seni masih melekat pada masyarakat kota Pekanbaru, baik dalam bentuk modern, tradisional, maupun kontemporer. Sehingga pentingnya pengembangan pendidikan di bidang seni itu dilanjutkan agar ciri khas seni kebudayaan Melayu, modern dan kontemporer yg ada dapat di tingkatkan.

Berdasarkan data kemendikbud, kota pekanbaru masih minim perguruan tinggi di bidang kesenian, tidak adanya pendidikan tinggi khusus yang mempelajari tentang kesenian. Di lihat dari perbandingan daerah di indonesia, bentuk perguruan tinggi di bidang kesenian yang paling mencolok dan berpotensi adalah Institut, maka dari itu di butuhkan lah sebuah Institut Kesenian Pekanbaru yang menjadi pondasi pendidikan kesenian tingkat perguruan tinggi di Kota Pekanbaru.

Institut Kesenian Pekanbaru dapat mewadahi kegiatan pendidikan tersebut mulai dari Seni Modern seperti Seni Tari, Seni Lukis, Desain Grafis, Arsitektur, Desain Komunikasi Visual, Perfilman, dan fotografi hingga Seni Tradisional seperti seni Tari tradisional, seni murni, serta seni musik tradisional.

Insitut Kesenian Pekanbaru memerlukan pendekatan yang dapat memaksimalkan perancangn bangunan. Maka di gunakan lah preseden dari karyakarya Arsitektur yang di desain oleh seorang arsitek Denmark bernama Bjarke Ingles dengan bantuan rekan-rekannya (BIG). Bjarke ingles merupakan seorang pendiri dari creative partner of Bjarke Ingles Group (BIG), sebuah perusahaan arsitektur ternama di dunia. Karya-karya yang di ambil sebagai preseden adalah Copenhill, Glasir Tórshavn College, dan MÉCA Cultural Center.

Copenhill merupakan contoh dari tolak ukur penulis mengenai sebuah bangunan fungsional yang dapat menjadi sebuah bangunan ikonik di kota yang memiliki kondisi fisik yang sama di kota Pekanbaru. Glasir Tórshavn College merupakan contoh dari tolak ukur penulis mengenai sebuah bangunan pendidikan dengan berbagai jurusan dapat terhubung dalam satu bangunan. $M E ́ C A$ merupakan contoh dari tolak ukur penulis mengenai sebuah bangunan kesenian yang menampilkan pameran atau event pada bagian luar dan dalam.

Perancangan Institut Kesenian Pekanbaru ini dengan preseden karya BIG ini menjadi sebuah anak tangga dalam melangkah ke dalam dunia Entertainment atau industri profesional di bidang kesenian, dan menjadi sebuah bangunan Landmark bagi kota Pekanbaru itu sendiri.

Institut Kesenian Pekanbaru merupakan sebuah organisasi atau perkumpulan yang bertujuan menyelenggarakan usaha pendidikan kesenian pada wilayah kota Pekanbaru.

Berdasarkan Peraturan Pemerintah No. 17 Tahun 2010 pasal 1 ayat 20 Institut adalah perguruan tinggi yang menyelenggarakan pendidikan akademik dan/atau pendidikan vokasi dalam sekelompok disiplin ilmu pengetahuan, teknologi, dan/atau seni dan jika memenuhi syarat dapat menyelenggarakan pendidikan profesi.

Dengan sejalannya perkembangan ilmu pendidikan dan kesenian, terdapat cabang seni sebagai berikut: 


\section{Seni Rupa}

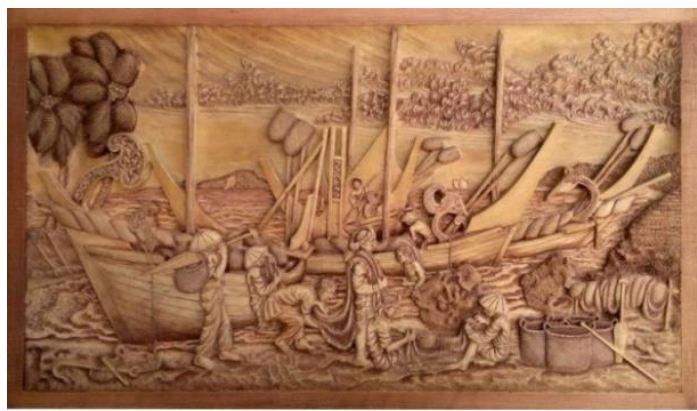

Gambar 1. Karya Seni Rupa

Sumber: https://bit.ly/2X8horG

Seni rupa murni pada dasarnya mengacu pada karya-karya yang hanya untuk tujuan pemuasan ekskresi pribadi, sementara seni kriya dan desain lebih menitik beratkan fungsi dan kemudahan dalam menjalankan produksinya (Badriya, 2017).

\section{Seni Pertunjukan}

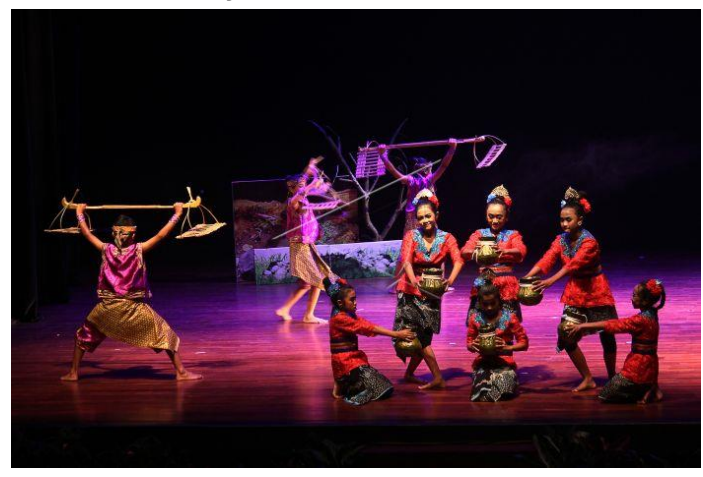

Gambar 2 Seni Pertunjukan Sumber: https://bit.ly/3aJVHIt

Merupakan salah satu bentuk seni yang kompkleks karena pada seni pertunjukan tidak hanya melibatkan satu 1 jenis namun komponennya melibatkan berbagai jenis karya seni. Seperti pada pertunjukan teater. Seni yang ditampilkan bukan hanya seni peran, melainkan gabungan antara seni peran, musik dan seni rias untuk kostum dan make up yang dikenakan para pemain. Seni pertunjukan tidak dapat berdiri sendiri maka dari itu seni ini disebut sebagai bentuk seni yang kompleks (Rulita,2017).

3. Seni Media Rekam

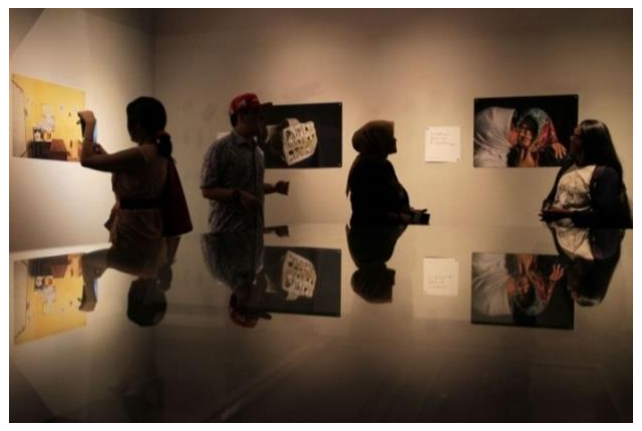

Gambar 3 Pameran Seni Media Rekam Sumber: https://bit.lv/2IC4U3k

Bidang seni yang memakai media untuk merekam, tegasnya kamera, entah film, video atau digital untuk mengeskpresikn gagasan atau perasaan seniman (Adiguna, 2012).

BIG adalah kelompok arsitek, perancang, pembangun dan pemikir yang berbasis di Copenhagen dan New York yang beroperasi di bidang arsitektur, urbanisme, penelitian, dan pengembangan. Kantor perusahaan saat ini terlibat dalam sejumlah besar proyek di seluruh Eropa, Amerika Utara, Asia dan Timur Tengah.

\section{Copenhill}

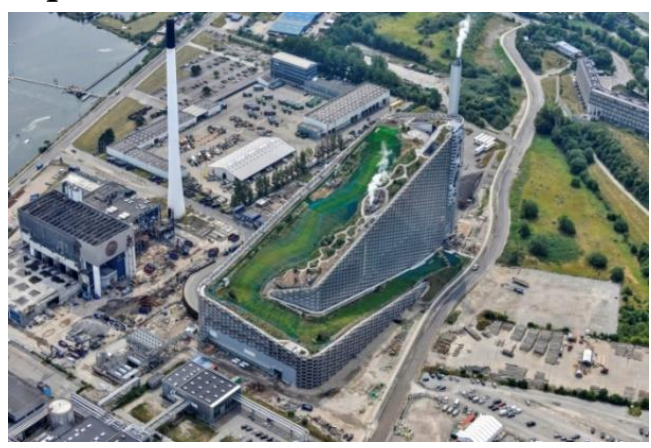

Gambar 4 Perspektif Mata Burung Copenhill Sumber: https://bit.ly/2x2VcEv

Copenhill atau Amager Bakke adalah sebuah bangunan Waste to Energy Plant yang berlokasi di Copenhagen, Denmark. Dirancang oleh firma Arsitektur bernama Bjarke Ingels Group (BIG) yang didirikan 
oleh seorang arsitek bernama Bjarke Ingels. Dengan total luas lantai 42 hektar, menghasilkan bangunan multi fungsi, selain menjadi Energy Plant, juga menjadi EcoTourisme dengan fasilitas ski, hiking, climbing wall pada bagian atapnya.

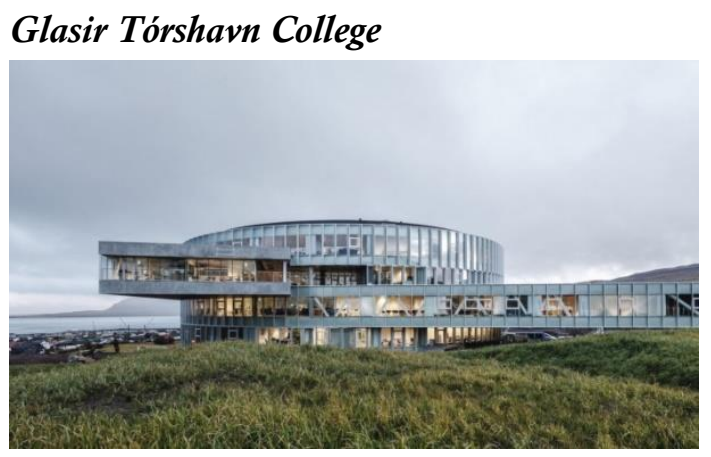

Gambar 5 Eksterior Bangunan Sumber: https://bit.lv/3g1CWgo

Terletak di Fjord, Kepulauan Faroe, dengan pemandangan ke ibukota Tórshavn, laut dan pepohonan hijau, Glasir berupaya menghasilkan sebuah efisiensi dengan menggabungkan Gymnasium Kepulauan Faroe, Tórshavn Technical College dan Business College of Faroe Islands menjadi satu gedung untuk lebih dari 1.750 siswa, guru, dan staff. Glasir mempertahankan otonomi dan identitas individu untuk masing-masing dari tiga sekolah, sambil menciptakan kondisi ideal untuk kolaborasi dan pembelajaran untuk berkembang.

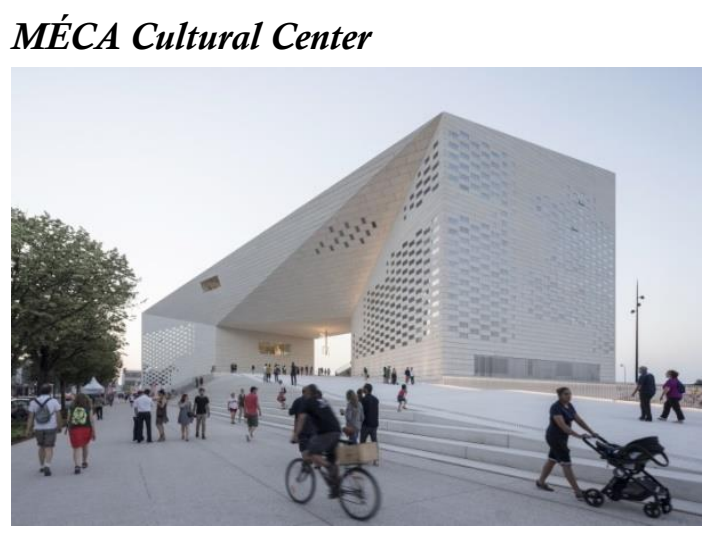

Gambar 6 Perspektif Mata Manusia Sumber: https://bit.ly/2WHR6vu
Maison de l'Économie Créative et de la Culture en Aquitaine atau disebut MÉCA, seluas $18.000 \mathrm{~m} 2$ menciptakan gambaran untuk perayaan seni, film, dan pertunjukan kontemporer, dan memberikan Bordeaux sebuah ruang publik yang penuh seni dari tepi laut ke kota yang baru. ruang kota. Berlokasi sentral di antara Sungai Garonne dan stasiun kereta Saint-Jean, MÉCA, menyatukan tiga agensi seni regional FRAC untuk seni kontemporer, ALCA untuk sinema, sastra, dan audiovisual, dan OARA untuk seni pertunjukan dalam suatu Loop, diperkuat dengan terdaftar di UNESCO-listed city sebagai The Epicenter For Culture.

\section{METODE PENELITIAN}

Perancangan Institut Kesenian Pekanbaru ini merupakan tanggapan dari kurangnya media lembaga pendidikan di bidang seni di pekanbaru, sehingga para anak muda lulusan SMA dapat memilih untuk belajar bagaimana menjadi pekerja Seni Profesional. Sehingga karya desain BIG di pilih sebagai pendekatan perancangan Insitut Kesenian Pekanbaru.

Adapun strategi perancangan Institut Kesenian Pekanbaru adalah melakukan studi Literatur pada tema perancangan terkait, Menganalisa gambaran mengenai fungsi Institut Kesenian Pekanbaru dan kegiatan apa saja yang terjadi di dalamnya, Menganalisa kelebihan, kekurangan, dan potensi site, membuat program ruang untuk memudahkan dalam mengklasifikasi pembagian ruangan untuk mengakomodasi berbagai macam kegiatan pelaku maupun event yang ada pada bangunan, Melakukan pembagian area/zona untuk berbagai macam kegiatan bangunan, membuat konsep yang merupakan dasar perancangan bangunan, membuat bentukan massa sebagai pedoman perancangan, 
memperhatikan tatanan ruang terutama pada sirkulasi dan pencapaian, merancang area landscape untuk mempermudah sirkulasi dan pengkhawaan bangunan, menyesuaikan bentukan fasad dengan konsep utama, membuat sirkulasi pejalanan kaki dan kendaraan dengan ketentuan yg ada, memilih stuktur yg sesuai dengan bentukan massa bangunan, merancang sistem utilitas bangunan yang mampu memaksimalkan penggunaan energi, sehingga menghasilkan hasil desain yang optimal.

\section{PEMBAHASAN}

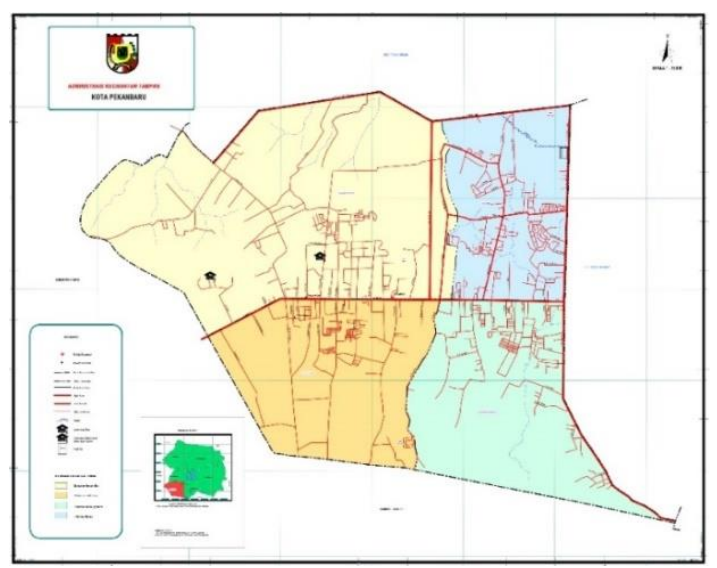

Gambar 7. Peta Wilayah Kecamatan Tampan

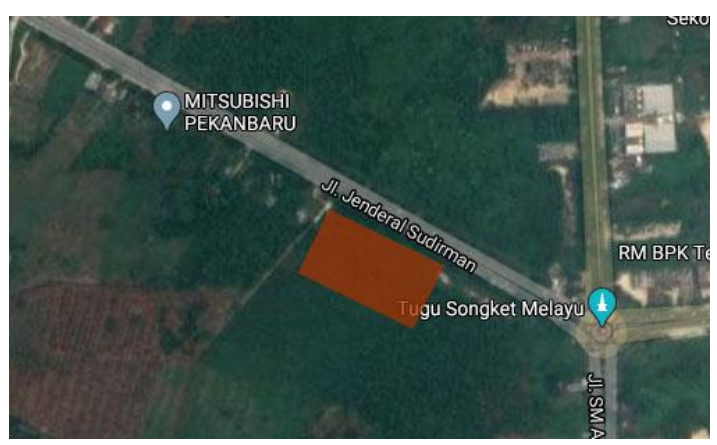

Gambar 8 Lokasi Site

Lokasi terpilih terletak pada tepi jalan Jenderal Sudirman/ jalan Tuanku Tambusai Ujung, Kecamatan Tampan, Pekanbaru, Riau. Pemilihan lokasi yang berluasan sekitar $50000 \mathrm{~m}^{2}$ ini didasari atas beberapa pertimbangan yaitu (a). Lokasi berdekatan dengan universitas riau, sehingga menjadi tempat berkumpulnya mahasiswa yang masih dalam usia produktif, (b). Lokasi site berdekatan dengan Terminal AKAP, sehingga akses bagi para mahasiswa, tamu dan masyarakat luar menjadi lebih mudah. (c). Lokasi site berdekatan dengan stadion utama riau yang selalu ramai dikunjungi masyarakat sekitar pekanbaru sebagai sarana olahraga, dan bersantai, (d). Akses lokasi menuju site merupakan jalan arteri yang relative besar sehingga dapat dilalui kendaraan umum.

\section{Analisa Site}

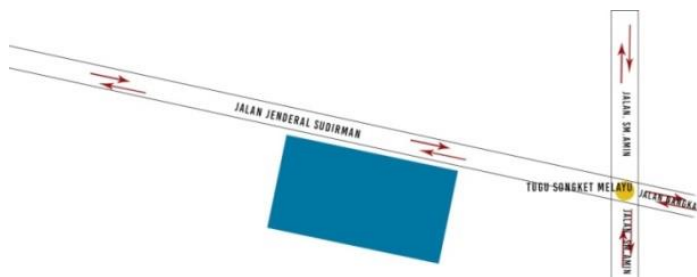

Gambar 9 Analisis Pencapaian Tapak

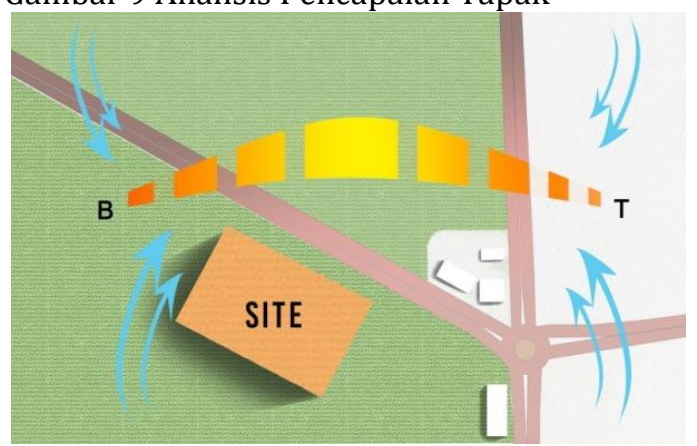

Gambar 10 Analisa Matahari dan Angin

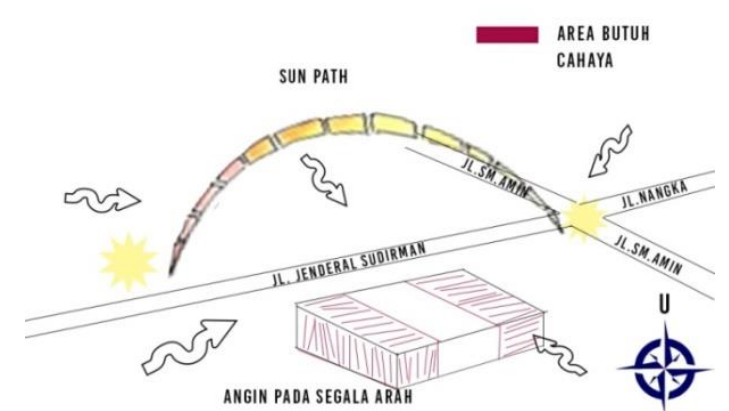

Gambar 11 Respon terhadap Cahaya dan Angin 


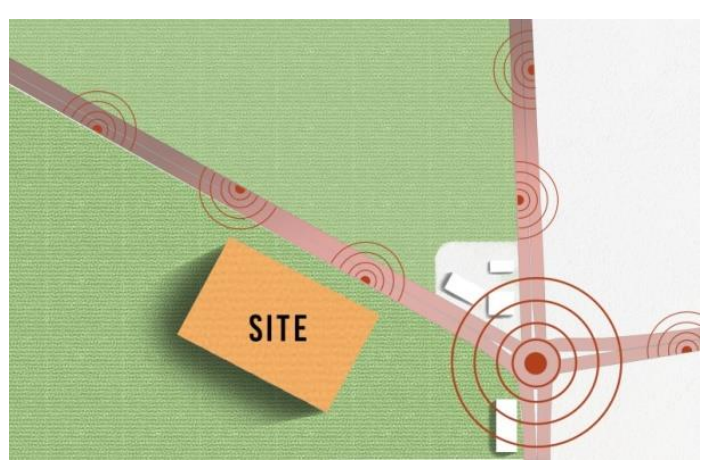

Gambar 12 Analisa Kebisingan

\section{AREA POHON}

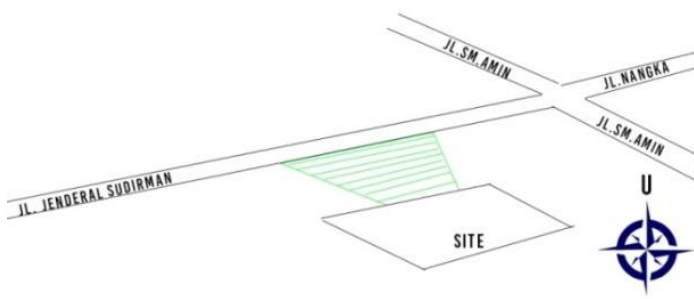

Gambar 13 Respon Kebisingan

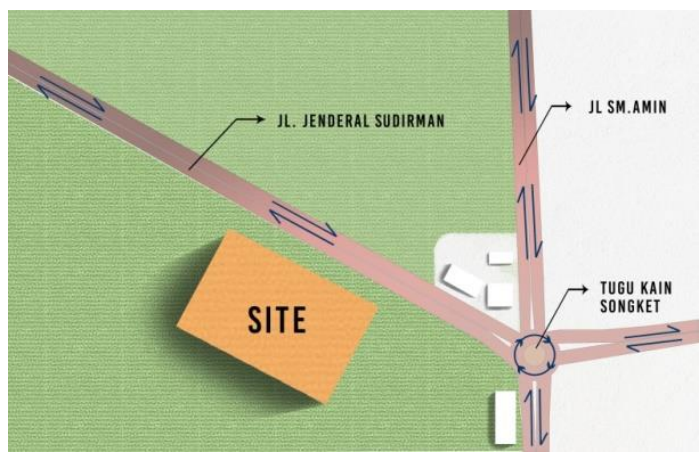

Gambar 14 Analisa Sirkulasi

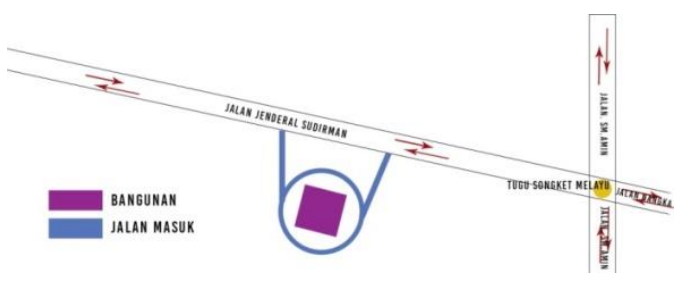

Gambar 15 Respon Sirkulasi

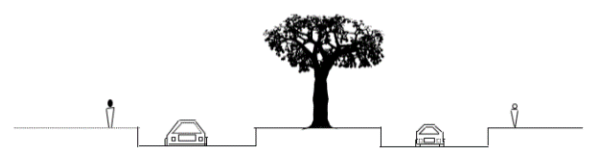

Gambar 16 Pedestrian

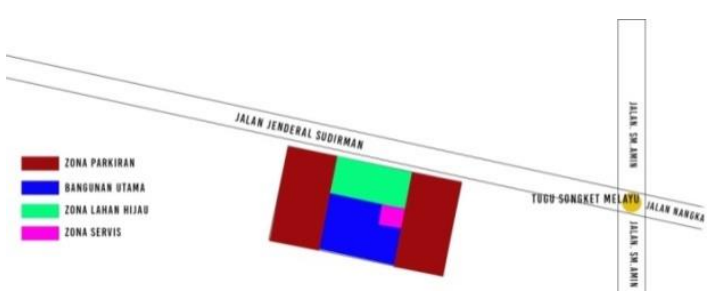

Gambar 17 Analisa Zoning

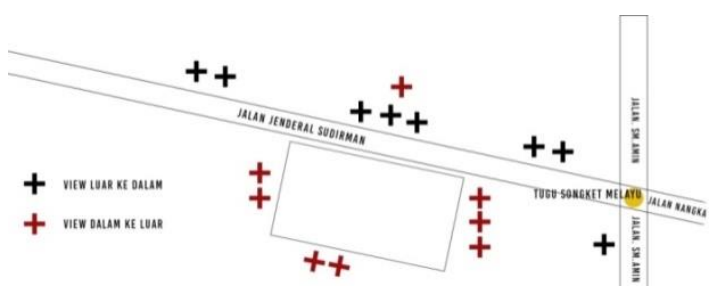

Gambar 18 Analisa View

Institut Kesenian Pekanbaru terdiri dari 5 fungsi, yaitu:

1. Fungsi Primer (Insitut Kesenian)

2. Fungis Sekunder (Edukasi dan Rekreasi Kesenian)

3. Fasilitas Penunjang (Fasilitas Mahasiswa)

4. Fasilitas Servis

5. Fungsi Tersier (Fasilitas Umum)

Tabel 1 Kebutuhan Ruang

\begin{tabular}{|l|l|l|}
\hline No & Kelompok Fasilitas & Luas $\left(\mathrm{m}^{2}\right)$ \\
\hline 1 & Fasilitas Primer & 12520 \\
\hline 2 & Rektorat & 2240 \\
\hline 3 & Fasilitas Sekunder & 600 \\
\hline 4 & Fasilitas Penunjang & 1480 \\
\hline 5 & Fasilitas Servis & 180 \\
\hline 6 & Fasilitas Tersier & 6330 \\
\hline \multicolumn{2}{|l|}{ Total Luas } & 23.170 \\
\hline
\end{tabular}

Sumber: Harya Bima Prasetya, 2020

Stuktur yang digunakan adalah tiang pancang, dikarenakan mampu menahan beban yang besar, sementara spaca frame yang mampu menahan beban pada rooftop. 


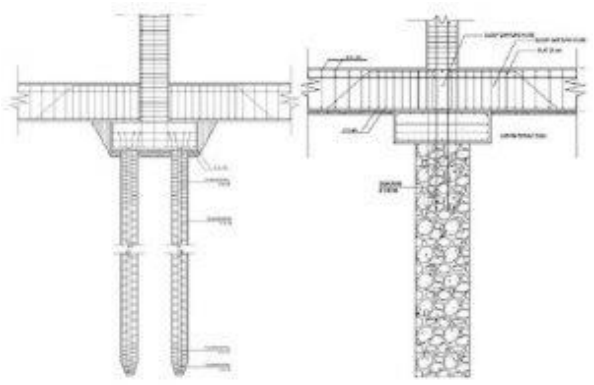

Gambar 19 Struktur Bawah

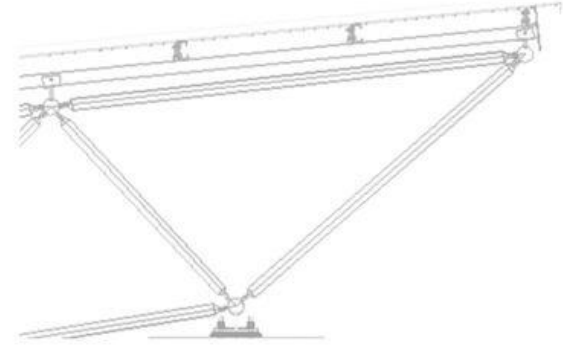

Gambar 20 Struktur Atas

Dengan penggunaan preseden karya BIG yang di nilai penulis cocok untuk menjadi tema dari Institut Kesenian Pekanbaru, maka diterapkan lah pada perancangan bangunan sebagai berikut.

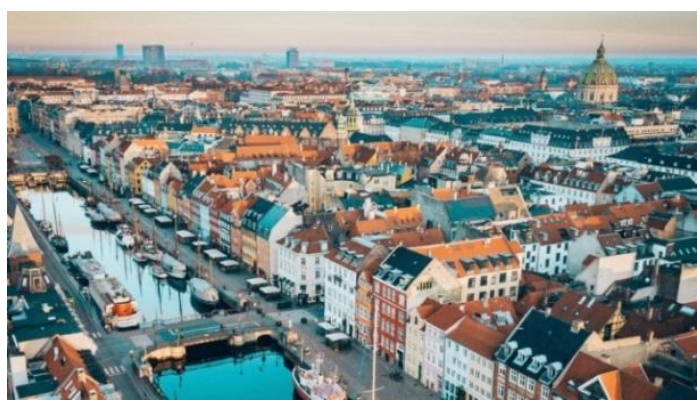

Gambar 21 Copenhagen Sumber: https://bit.ly/34iiWRm

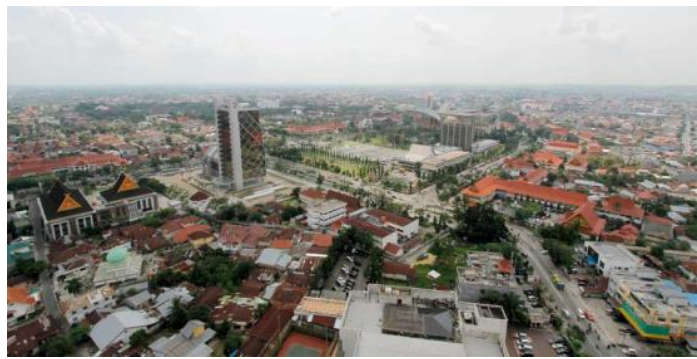

Gambar 22 Pekanbaru Sumber: https://bit.ly/3c12GHa
Pada aspek Preseden Copenhill memperhatikan bagaimana cara pemilihan Site. Sehingga pada site perancangan yang dipilih berdekatan dengan area pendidikan, sehingga sejumlah anak muda kreatif bisa saling memberi informasi dan berkreasi. Institut Kesenian Pekanbaru berdekatan dengan Universitas Riau, UMRI, dan UIN SUSKA. Prinsip Hedonistic Sustainability Bangunan ini juga diperhatikan. Sehingga pada penerapannya, bangunan dirancang atas kebutuhan masyarakat terhadap media pendidikan formal di bidang kesenian, dengan fungsi sekunder menjadi tempat rekreasi dan edukasi, yaitu pameran umum hasil karya mahasiswanya di tiap fakultas masing. Serta tempat bersantai berupa elemen hijau berupa penggunaan rumput pada area rooftop nya. Selain dampak positif yang di hasilkan, Institut Kesenian Pekanbaru juga merupakan peringatan ke masyarakat mengenai pencemaran limbah pada sungai siak, dengan cara memberikan warna coklat dan material kayu gelap sebagai warna sungai yang tercemar.

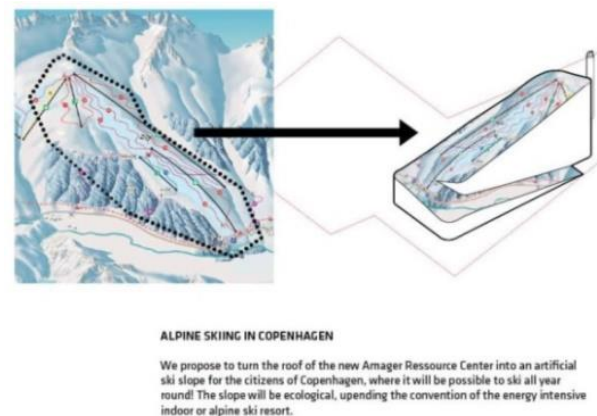

Gambar 23 Konsep Copenhill Sumber: https://bit.lv/3dWHZxF

Penerapan Konsep Alam, pada Institut Kesenian Pekanbaru menggunakan konsep yang berasal dari alam, yaitu Sungai Siak, yang mengalir di provinsi Riau. Pemilihan konsep ini berdasarkan pertimbangan dari Copenhill yang menggunakan alam untuk dijadikan konsep. 


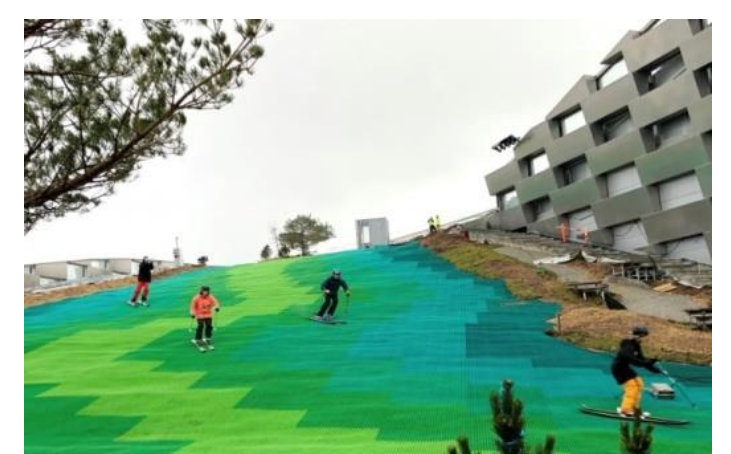

Gambar 24 Area Ski

Sumber: https://bit.ly/3bYWAa8

Multi Fungsi, Institut Kesenian

Pekanbaru menjadi bangunan multifungsi, dengan fungsi utama perguruan tinggi di bidang kesenian dan fungsi sekunder sebagai tempat rekreasi, yaitu taman rekreasi dan edukasi berupa pameran karya mahasiswa.

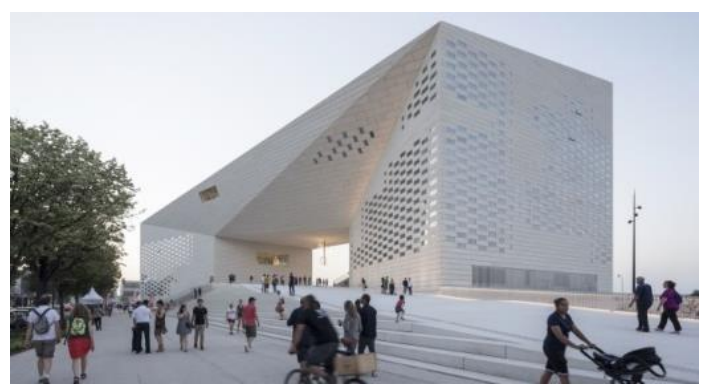

Gambar 25 MECA

Sumber: https://bit.ly/2WHR6vu

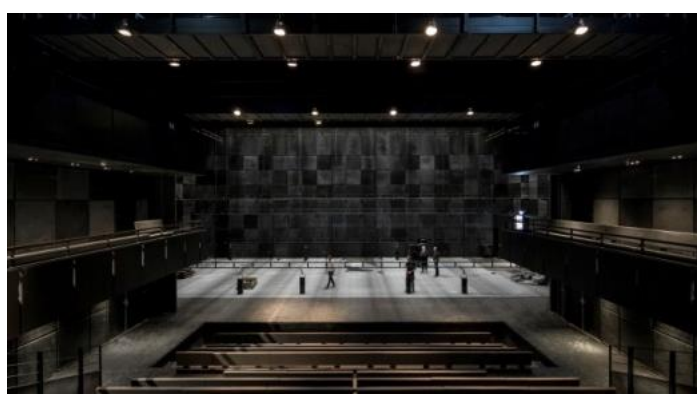

Gambar 26 Interior MECA Sumber: https://bit.ly/3cJLgPR

Pada aspek MECA, penggunaan ekspos kesenian pada Insitut Kesenian Pekanbaru menggunakan pertimbangan pemilihan material yang mengekspos teksturenya seperti beton pada area tertentu baik dalam maupun luar bangunan. Dan juga menggunakan ruang bangunan preseden sebagai inspirasi.

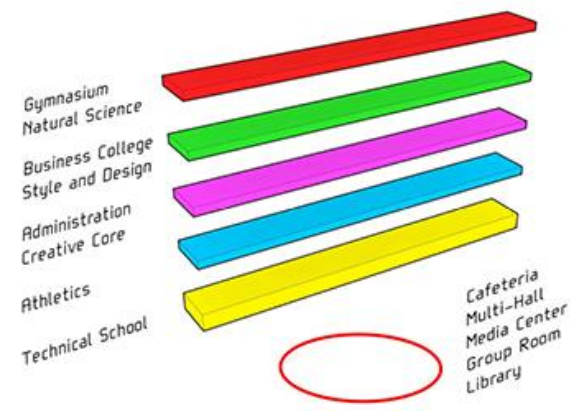

Gambar 27 Layers

Sumber: https://bit.ly/2AEBjVX

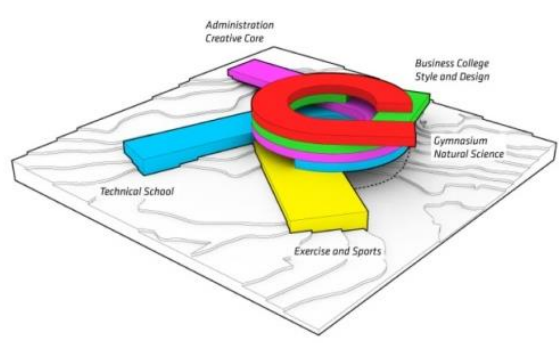

Gambar 285 of Stack and Vortex Sumber: https://bit.ly/2LFnnNH

Pada aspek Glasir Tórshavn College adalah Organisasi Ruang. Setiap lantai di sesuaikan dengan jurusan yang berbeda, sehingga menjadi tataan yang rapi, fungsional, dan efisien. Pada tiap fakultas di berikan masing-masing 1 massa yang di rancang seefisien mungking secara organisasi ruang dan sirkulasi.

Konsep dari perancangan ini adalah Polygon River, hal ini di dasari dengan pemikiran oleh keunikan alam di sekitar area Site yaitu Kota Pekanbaru berupa sebuah sungai yang seharusnya berupa lengkungan menjadi sebuah bentukan bangunan yang bersudut berbentuk poligon. 


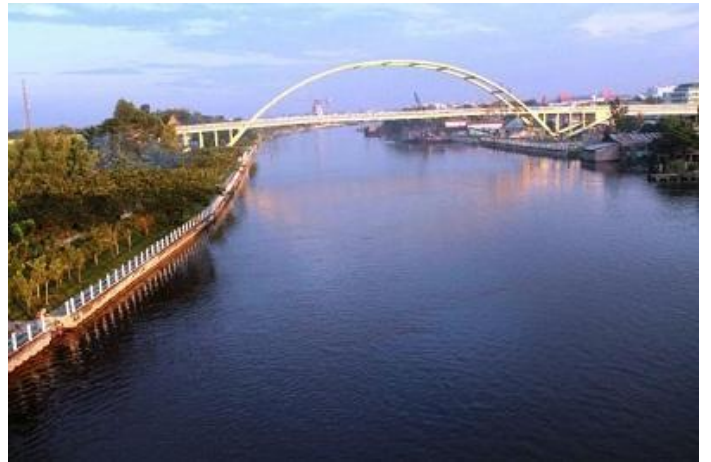

Gambar 29 Sungai Siak

Sumber: https://bit.ly/2xaQ2GI
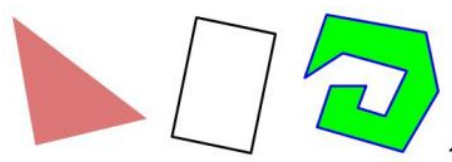

Gambar 30 Poligon

Sumber: https://bit.ly/3c33JXc

Bentukan massa Institut Kesenian Pekanbaru menggunakan konsep dasar dari bentukan sungai yang di transformasikan dari garis lengkung menjadi sebuah garis patah-patah atau di sebut poligonisasi. Penerapan aspek-aspek sungai siak pada Insitut Kesenian Pekanbaru adalah sebagai berikut:

1. Belokan Sungai, merupakan bentukan sungai yang melengkung secara tak beraturan.

2. Pasang Surut, merupakan naik turun nya permukaan air.

3. Warna Air, merupakan tampilan sungai Siak secara visual.

4. Kedalaman, merupakan ukuran dari permukaan tanah ke dasar sungai.

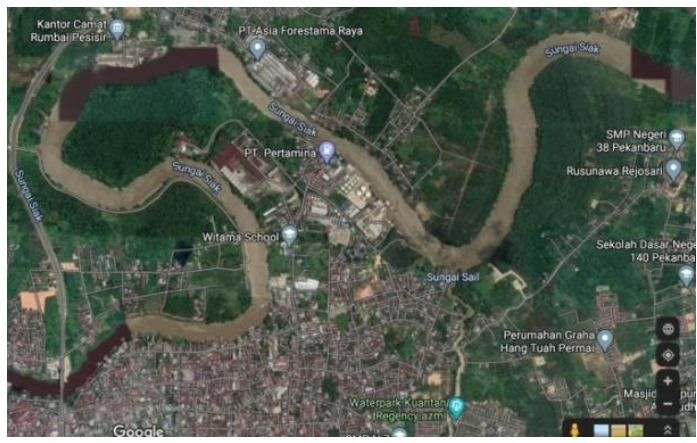

Gambar 31 Bagian Sungai Siak

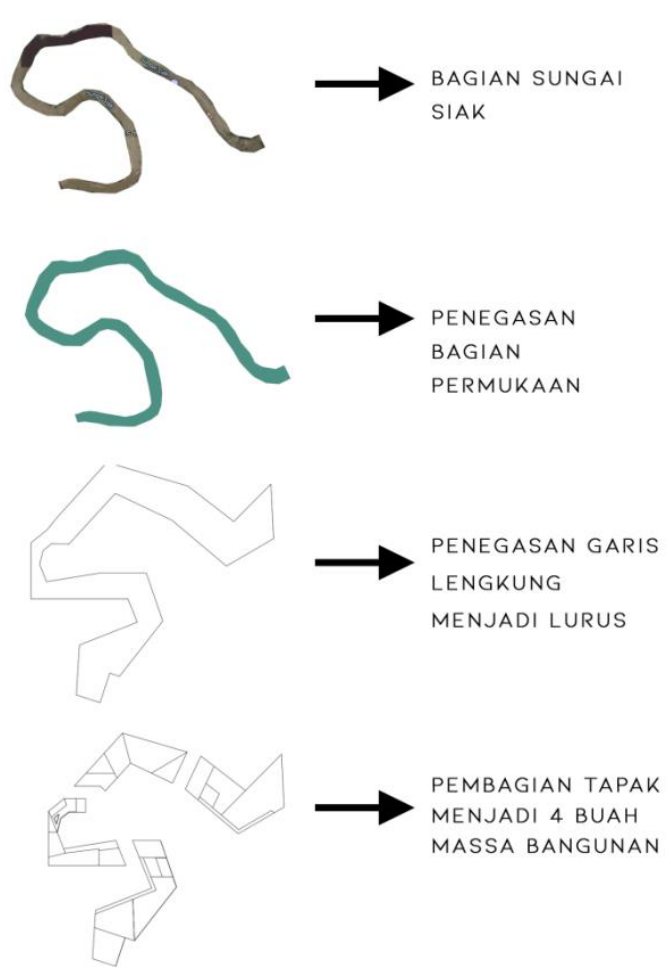

Gambar 32 Transformasi Horizontal

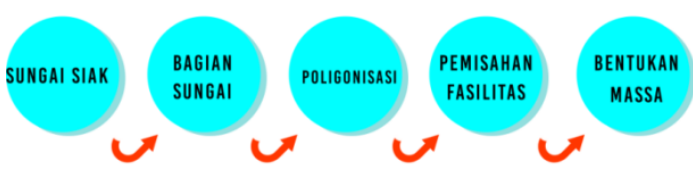

Gambar 33 Skema pembentukan Tema
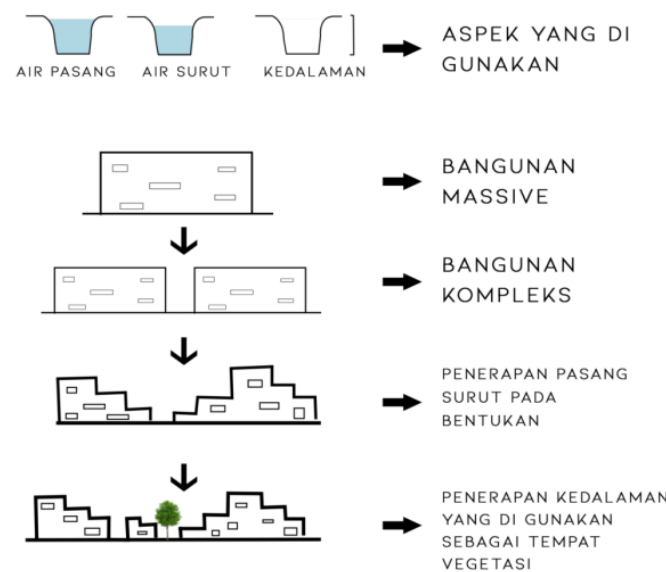

Gambar 34 Transformasi Vertikal

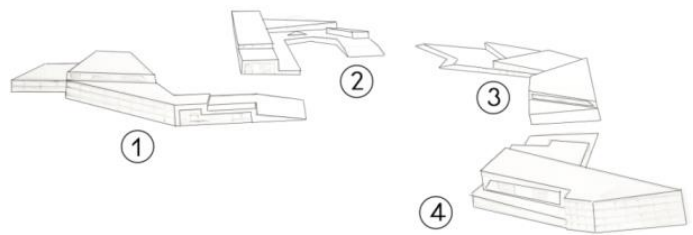

Gambar 35 Bentukan Massa Kawasan 


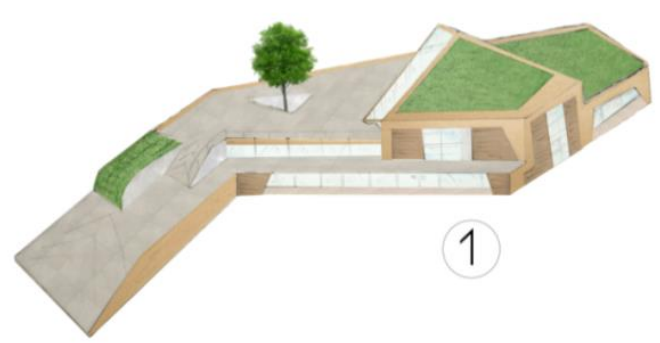

Gambar 36 Fakultas Seni Rupa dan Desain

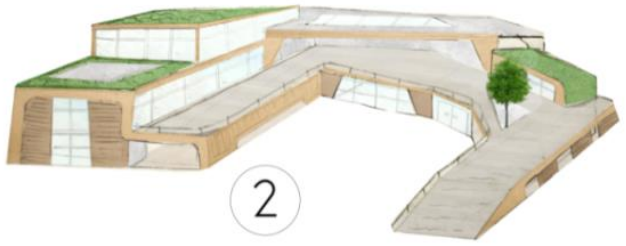

Gambar 37 Fakultas Seni Pertunjukan

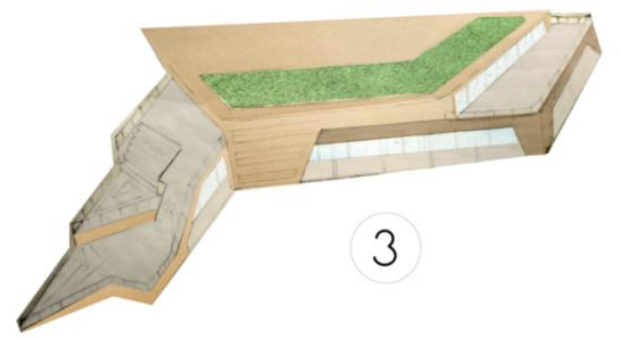

Gambar 38 Fakultas Film dan Televisi

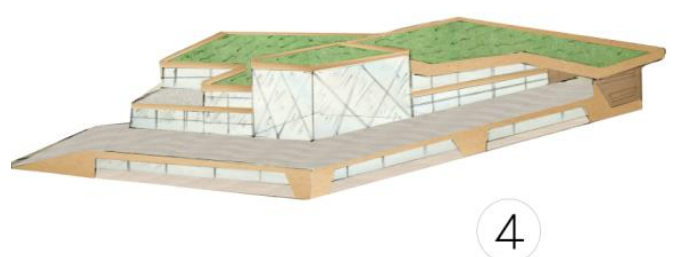

Gambar 39 Rektorat

\section{Konsep Facade}

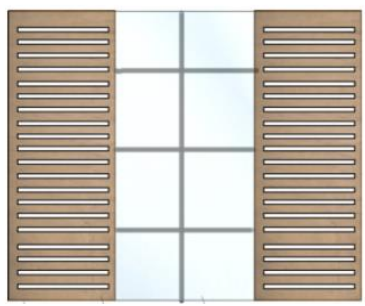

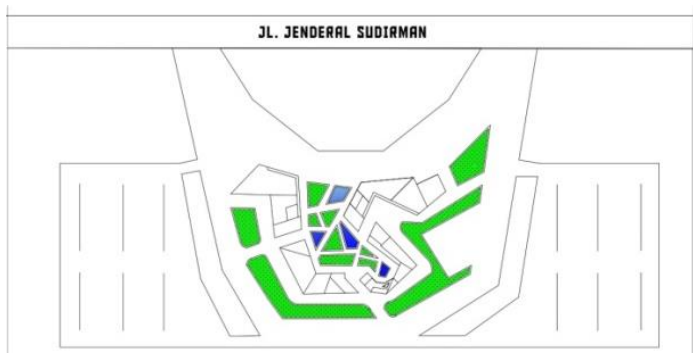

Gambar 40 Tampilan Landscape

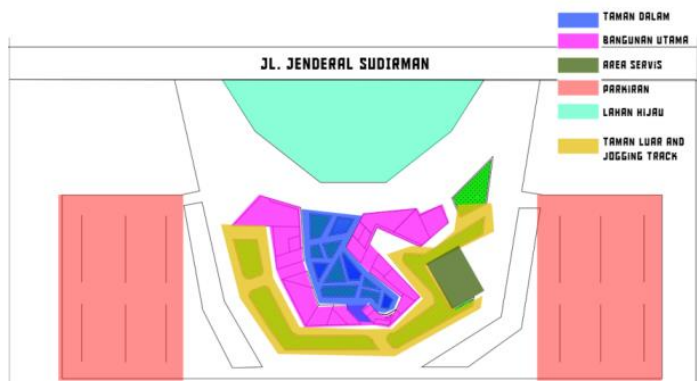

Gambar 41 Zoning

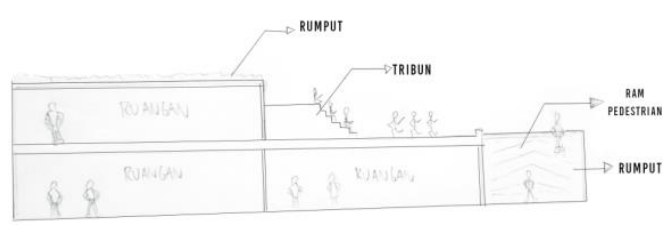

Gambar 42 Konsep Vegetasi Bangunan area atap

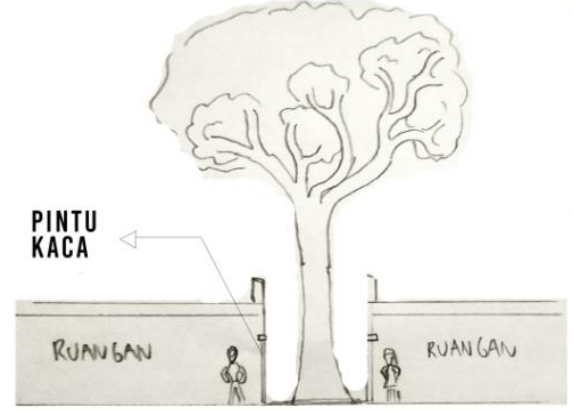

Gambar 43 Konsep Vegetasi pada area inti bangunan

\section{Konsep Sirkulasi}

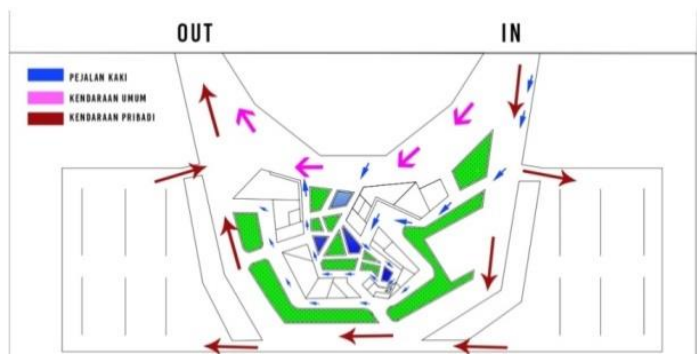

Gambar 44 Konsep Sirkulasi 


\section{Konsep Ruang Interior}

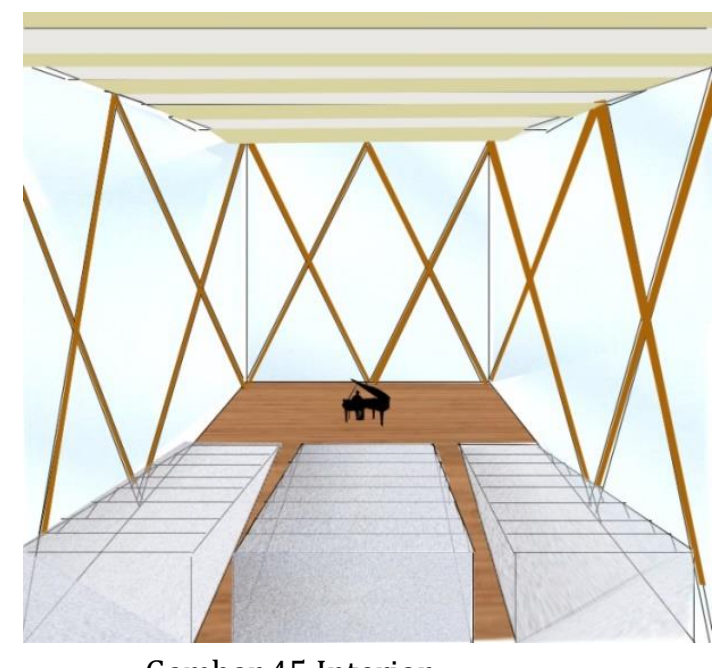

Gambar 45 Interior

\section{SIMPULAN}

Institut Kesenian Pekanbaru dengan Preseden karya BIG dirancang untuk mewadahi para anak muda pecinta seni dalam meneruskan pendidikan di bidang kesenian dengan memberikan fasilitas sesuai dengan cabang seni yang diminati. Penerapan preseden karya BIG dengan multi fungsional, selain dari fungsi utama sebagai perguruan tinggi, juga dapat menjadi sebuah Public Space berupa rekreasi dan edukasi bagi para masyarakat umum. Seperti pertunjukan terbuka, Open Screen, dan Pameran beserta taman. Institut Kesenian Pekanbaru juga menerapkan cara pengambilan konsep dan prinsip desain dari preseden karya BIG berupa pengambilan bagian fisik dari alam sekitar yaitu sungai yang di anggap sebagai ciri khas pada area site. Serta penerapan prinsip desain Hedonistic Sustainability berupa pertimbangan bangunan perancangan terhadap lingkungan sekitar, terutama pada dampak yang di hasilkan. Seperti memperlihatkan hasil dari kesenian itu sendiri kemasyarakat umum pada bagian Facade dan akses pedestrian ke area rooftop yang berupa tempat pertunjukan dan pameran umum sehingga masyarakat dapat menikmati hasil dari kreativitas kesenian dari para pelaku seni.

\section{DAFTAR PUSTAKA}

Adiguna, Leistar. FFD dan Masa Depan Seni Media Rekam. Diakses dari https://www.academia.edu/31104199/FFD_ dan_Masa_Depan_Seni_Media_Rekam

Badriya, Yaya. (2017). Cabang Seni Rupa - Contoh dan Penjelasanya. Diakses dari https://ilmuseni.com/seni-rupa/cabang-senirupa

Badan Perfilman Indonesia. Tentang BPI. Diakses dari bpi.or.id. https://www.bpi.or.id/tentang.html pada tanggal 5 April 2020

Bjarke Ingels Group. (2019). ARC Copenhill/Amager Bakke. Diakses dari https://big.dk/\#projectsarc

Bjarke Ingels Group. (2018). Glasir Tórshavn College. Diakses dari https://big.dk/\#projects-faer

Bjarke Ingels Group. (2018). MÉCA Cultural Center / BIG. Diakses dari https://big.dk/\#projectsmeca

Dokumen RTRW Kota Pekanbaru. BAPPEDA Kota Pekanbaru, Pekanbaru

Ismarani, Dian. (2016). Apa Sih Beda Antara Universitas, Institut, Sekolah Tinggi, Politeknik dan Akademi. Diakses dari https://rencanamu.id/post/review/apa-sihbeda-antara-universitas- institut-sekolahtinggi-politeknik-dan-akademi

Kementrian Pendidikan dan Budaya. jumlah data satuan pendidikan (sekolah) tinggi per kabupaten/kota : Kota Pekanbaru. Diakses dari.

https://referensi.data.kemdikbud.go.id/index 51.php?kode $=096000 \&$ level $=2$ pada tanggal 12 April 2020

Mugiwara, Dani. Kesenian Adalah?. Diakses dari https://mediacerita.com/kesenian-adalah/

Peraturan Pemerintah No. 17 Tahun 2010 tentang Pengelolaan dan Penyelenggaraan Pendidikan. Lembaran Negara Republik Indonesia Tahun 2003 Nomor 78, TambahanLembaran Negara Republik Indonesia Nomor 4301.

Rulita. (2017). Pengertian Seni Pertunjukan Menurut Para Ahli Terlengkap. Diakses dari https://ilmuseni.com/senipertunjukan/pengertian-seni-pertunjukanmenurut-para-ahli. . 